\title{
Comparable Growth of Tritrichomonas mobilensis in Two Commercially Available Culture Media
}

\author{
Author(s): Andrea K. Boggild , Christine A. Sundermann , Barbara H. Estridge, and David S. Lindsay \\ Source: Journal of Parasitology, 88(5):1012-1014. 2002. \\ Published By: American Society of Parasitologists \\ DOI: http://dx.doi.org/10.1645/0022-3395(2002)088[1012:CGOTMI]2.0.CO;2 \\ URL: http://www.bioone.org/doi/full/10.1645/0022-3395\%282002\%29088\%5B1012\%3ACGOTMI \\ $\% 5 \mathrm{D} 2.0 . \mathrm{CO} \% 3 \mathrm{~B} 2$
}

BioOne (www.bioone.org) is a nonprofit, online aggregation of core research in the biological, ecological, and environmental sciences. BioOne provides a sustainable online platform for over 170 journals and books published by nonprofit societies, associations, museums, institutions, and presses.

Your use of this PDF, the BioOne Web site, and all posted and associated content indicates your acceptance of BioOne's Terms of Use, available at www.bioone.org/page/terms_of_use.

Usage of BioOne content is strictly limited to personal, educational, and non-commercial use. Commercial inquiries or rights and permissions requests should be directed to the individual publisher as copyright holder. 


\title{
Comparable Growth of Tritrichomonas mobilensis in Two Commercially Available Culture Media
}

\author{
Andrea K. Boggild, Christine A. Sundermann*, Barbara H. Estridge*, and David S. Lindsay†, Room 2124 Medical Sciences Building, 1 \\ King's College Circle, Faculty of Medicine, University of Toronto, Ontario, Canada M5S 1A8; *Department of Biological Sciences, 131 Cary \\ Hall, Auburn University, Alabama 36849; †Department of Biomedical Sciences and Pathobiology, Virginia-Maryland Regional College of \\ Veterinary Medicine, Virginia Tech, Blacksburg, Virginia 24061-0342. e-mail: andrea.boggild@utoronto.ca
}

\begin{abstract}
The investigation reported herein was undertaken to determine which medium is more practical for the axenic laboratory culture of trichomonads. The growth of Tritrichomonas mobilensis was monitored in 2 different types of commercially available growth media. Although Roswell Park Memorial Institute (RPMI) 1640 medium is typically used as a mammalian cell culture medium, it was found to support the growth of trichomonads as well as the American Type Culture Collection (ATCC) medium 745 under similar conditions. Environmental variables, such as temperature and $\mathrm{pH}$, known to affect the success of trichomonad cultures were controlled. The mean generation times (MGTs) of T. mobilensis in the log phase of growth were 5.1 and 4.9 hr for RPMI 1640 and ATCC medium 745, respectively. A stationary phase of zero growth was reached more quickly in the ATCC medium 745 cultures, and in both media a phase of rapid attrition followed this period of static growth. In assessing the practicality of the media, total cell amplification, as well as factors such as cost, ease of preparation, and storage capacity, were considered.
\end{abstract}

In vitro cultivation of trichomonads has been a useful tool in the diagnosis of sexually transmitted trichomoniasis (Lossick, 1988), which infects close to 200 million women worldwide (Krieger et al., 1988). The 2 most frequently used trichomonad culture media are Kupferberg's (Thomason et al., 1988) and modified Diamond's TYI-S-33 (Diamond et al., 1978). Although these media have been approved by the FDA for clinical diagnostic use, with the sensitivity of modified Diamond's medium approaching 100\% (Gelbart et al., 1990), their utility in the laboratory culture of nonvenereal trichomonads is questionable. Tritrichomonas mobilensis is an enteric tritrichomonad isolated from the large intestine of the Bolivian squirrel monkey Saimiri boliviensis boliviensis (Culberson et al., 1986). Although it is not known to infect humans, it can serve as a convenient model for research on other flagellated human pathogens. The recommended medium for axenic cultivation of $T$. mobilensis is the American Type Culture Collection (ATCC) medium 745, which is essentially a modified form of Diamond's medium (Diamond et al., 1978). The limitations of this type of medium include a very short shelf life ( $<14$ days), costly ingredients, and a need to autoclave once prepared. Conversely, the Roswell Park Memorial Institute (RPMI) 1640 medium can be purchased as a sterile liquid, has a very long shelf life (several months), and needs only to be supplemented with $10 \%$ fetal bovine serum (FBS). Additionally, RPMI 1640 medium lacks ingredients such as agar, which increase the viscosity of the medium, thus hampering trichomonad motility and dispersion throughout the culture tube.

In any culture, a lag phase, a log phase, and then a stationary phase of growth can be observed (Rainis, 1976). It is important to consider that each of these phases, as well as the culture doubling time, is affected by variables such as $\mathrm{pH}$, temperature, and other environmental parameters (Rainis, 1976). Thus, when comparing 2 different types of culture media, it is imperative that environmental perturbations and variables be strictly controlled. This study investigates which medium is more practical (in terms of generation time, cost, ease of use) for in vitro cultivation of tritrichomonads.

In the preexperimental phase, triplicate samples of $T$. mobilensis (ATCC \#50116, strain USA:M776) were inoculated in 15-ml screwcap culture tubes filled with either $10 \mathrm{ml}$ 10\% RPMI (RPMI 1640 with $0.03 \%$ L-glutamine [Fisher Scientific, Pittsburgh, Pennsylvania], $100 \mathrm{IU}$ penicillin, $100 \mu \mathrm{g} / \mathrm{ml}$ streptomycin, $1 \mathrm{mM}$ sodium pyruvate, $100 \mu \mathrm{g} / \mathrm{ml}$ amphotericin $\mathrm{B}$, and 10\% FBS [Hyclone Inc.,
Logan, Utah]) or $9.5 \mathrm{ml}$ ATCC medium 745 plus $0.5 \mathrm{ml}$ horse serum. The cultures were maintained at $37 \mathrm{C}$ and monitored for growth by frequent sampling over a period of $2 \mathrm{wk}$. Fresh cultures were inoculated every $48 \mathrm{hr}$ with $50 \mu \mathrm{l}$ inoculum. After the cultures had been sustained for at least $2 \mathrm{wk}$ (minimum of 7 subcultures), fresh 1-ml cultures (maintained in $1.5-\mathrm{ml}$ microfuge tubes) were inoculated with $5 \mu \mathrm{l}$ inoculum and incubated at $37 \mathrm{C}$.

Preliminary $1-\mathrm{ml}$ cultures were counted at $24 \mathrm{hr}$ using a hemacytometer. The cultures were mixed by inversion, and the sampled trichomonads were fixed in 5\% formalin before counting. Five thousand cells from each preliminary culture (10\% RPMI and ATCC medium 745) were transferred to new 1-ml tubes with fresh media. Starting at $24 \mathrm{hr}$, and every $12 \mathrm{hr}$ thereafter, the cultures were sampled and quantitated using a hemacytometer. Four corners of 5 hemacytometers were enumerated using a light microscope at each time interval. The highest and lowest counts were excluded, and the remaining 18 counts were averaged to yield trichomonad density per milliliter of medium. The organisms were fixed in formalin before quantitation. To avoid counting dead cells, 48-hr cultures and more were transferred to new, sterile culture tubes before being inverted and mixed. The dead cells were thus left sedimented at the bottom of the original culture tube. This experiment was repeated in triplicate. In addition, 12 high-density cultures were created ( 6 of each type of media) by inoculating fresh media $(1 \mathrm{ml})$ with 500,000 cells and then enumerating them at $48 \mathrm{hr}$ as described previously.

The generation time was calculated by using the equation of Johnson and Trussell (1944):

$$
\mathrm{G}=\mathrm{t} /[3.3 \log (\mathrm{b} / \mathrm{B})] .
$$

In this equation, $\mathrm{t}$ represents the interval in hours, $\mathrm{b}$ is the population of trichomonads per milliliter at the end interval, and B represents the population of trichomonads per milliliter at the beginning interval. ATCC medium 745 and 10\% RPMI growth parameters were compared using the test for differences between 2 population means (Student's 2tailed $t$-test). The significance was set at $P<0.05$.

The generation time of trichomonads cultured in 10\% RPMI varied from $4.3 \pm 0.08 \mathrm{hr}$ during the initial $\log$ phase to $10.1 \pm 1.2 \mathrm{hr}$ at the end of the log phase (Table I). The mean generation time (MGT) for the entire log phase of growth in 10\% RPMI was $5.1 \pm 0.05 \mathrm{hr}$. Conversely, in ATCC medium 745 the initial log-phase generation time was $4.2 \pm 0.07 \mathrm{hr}$, whereas the end log-phase generation time was $10.8 \pm$ $0.3 \mathrm{hr}$ (Table I). The entire log-phase MGT was $4.9 \pm 0.03 \mathrm{hr}$ in the ATCC medium 745 culture. At $24 \mathrm{hr}$ the mean density in the $10 \%$ RPMI culture was slightly less than in ATCC medium 745 (Fig. 1). At $48 \mathrm{hr}$ the $10 \%$ RPMI culture achieved a maximum density of $1.1 \times 10^{6}$ fewer trichomonads per milliliter than did the ATCC medium 745 (Fig. 1). High-density cultures, i.e., those inoculated with 500,000 cells, achieved similar maximum densities at $48 \mathrm{hr}$ as compared with those inoculated with 5,000 trichomonads in both types of culture media (Table II). In turn, the MGTs for the high-density (HD) cultures were significantly greater than those for the low-density (LD) cultures, again, in both types of culture media (Table III).

The results reported herein illustrate that the culture of T. mobilensis can be accomplished equally well with either $10 \%$ RPMI medium or ATCC medium 745. Although total amplification of the culture was greatest in ATCC medium $745(P<0.0001)$, as evidenced by slightly but significantly shorter generation times in the log growth phase $(P<$ 0.0001 ), a period of zero growth followed by precipitous attrition was reached more quickly in the ATCC medium 745 culture. Trichomonad 
TABLE I. MGT (hr) of Tritrichomonas mobilensis in 2 types of culture media. MGT of T. mobilensis in the $\log$ phase of growth (first $48 \mathrm{hr}$ ) was $5.1 \pm 0.05 \mathrm{hr}$ in $10 \% \mathrm{RPMI}$ and $4.9 \pm 0.03 \mathrm{hr}$ in ATCC medium 745 .

\begin{tabular}{lccc}
\hline & \multicolumn{3}{c}{ Mean generation time (hr) } \\
\cline { 2 - 4 } & Interval & Interval & Interval \\
& $1(0-24)$ & $2(24-36)$ & $3(36-48)$ \\
\hline 10\% RPMI & $4.3 \pm 0.08$ & $4.6 \pm 0.2$ & $10.1 \pm 1.2$ \\
ATCC 745 & $4.2 \pm 0.07$ & $4.1 \pm 0.3$ & $10.8 \pm 0.3$ \\
\hline
\end{tabular}

generation time is affected by many variables, including initial cell density (Meysick and Garber, 1990), temperature, pH (Kostara et al., 1998), and particularly, the type of medium in which the organisms are cultured. In Kupferberg's and modified Diamond's media, Trichomonas vaginalis has an MGT of $5.6 \mathrm{hr}$ in the log phase of growth (Gelbart et al., 1990). Conversely, when cultured in Feinberg and Whittington media, the MGT of T. vaginalis can range from 9.4 to $14.4 \mathrm{hr}$ in the $\log$ growth phase (Kostara et al., 1998). The MGT of T. mobilensis in both $10 \%$ RPMI and ATCC medium 745 was found to fall within the range of $T$. vaginalis, with average log-phase MGTs of 5.1 and $4.9 \mathrm{hr}$, respectively. Like T. mobilensis, T. vaginalis reached a stationary phase sometime between 48 and $60 \mathrm{hr}$ in both TYI-S-33 and PEHPS (peptona de caseína, extracto de hágado y páncreas, suero bovino) media (CastroGarza et al., 1996), as well as in Feinberg and Whittington media (Kostara et al., 1998). In each case this phase of zero growth quickly transitioned into one of rapid death (Castro-Garza et al., 1996; Kostara et al., 1998).

Initial density is another factor that greatly influences the generation time of trichomonads, although the total number of cells that a growth medium will support seems unaffected by the number of organisms present in the inoculum. In $T$. vaginalis, $\mathrm{LD}$ cultures have an average generation time of $6.5 \mathrm{hr}$, whereas in HD cultures the MGT escalates to $11.7 \mathrm{hr}$ (Meysick and Garber, 1990). Similar findings are reported herein, i.e., as the initial density of trichomonads increases, so too does the MGT (Table III). That maximum density was unaffected by initial density indicates that the carrying capacity for $T$. mobilensis is reached at about 3.5 million trichomonads per milliliter in 10\% RPMI medium and at 4.5 million trichomonads per milliliter in ATCC medium 745 . Further amplification of the culture is not seen after $48 \mathrm{hr}$, which suggests that at these densities, food, space, or other sustentative factors are limited.

In determining the success of a culture, factors beyond total cell growth and generation time must be considered. From a practical stand-

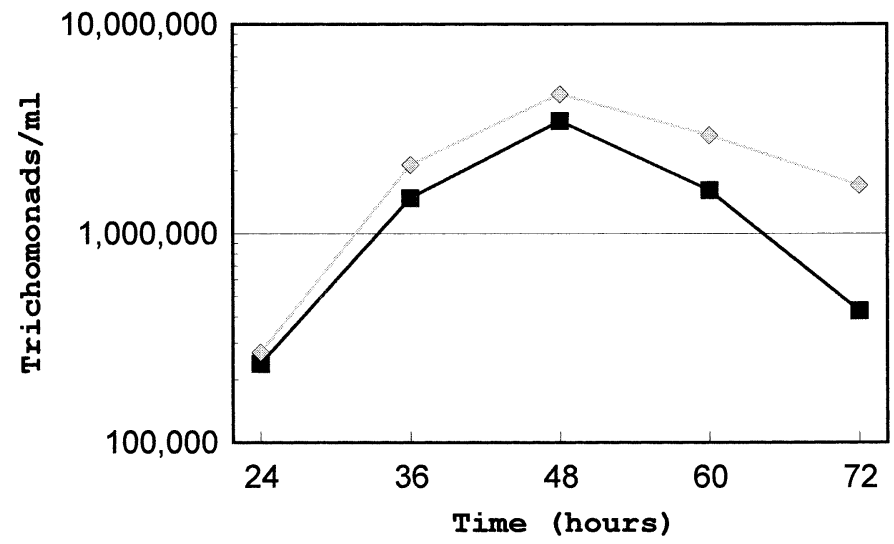

FIGURE 1. Mean trichomonad density in 10\% RPMI and ATCC medium 745 versus time (hr): $\mathbf{m}$ 10\% RPMI; $\diamond$, ATCC Medium 745. Note that in each culture medium, maximum density was achieved at $48 \mathrm{hr}$, with the 10\% RPMI culture supporting 3.5 million trichomonads per milliliter and the ATCC 745 medium supporting 4.6 million trichomonads per milliliter.
TABLE II. Mean density of Tritrichomonas mobilensis at $48 \mathrm{hr}$ in both high- and low-density cultures versus medium type. Note that the density at $48 \mathrm{hr}$ was unaffected by inoculum density, i.e., both high- and low-density cultures achieved insignificantly different cell densities at $48 \mathrm{hr}$.

\begin{tabular}{lcc}
\hline \multicolumn{2}{c}{ Density of inoculum } \\
\cline { 2 - 3 } & $\begin{array}{c}\text { High density } \\
5.0 \times 10^{5}\end{array}$ & $\begin{array}{c}\text { Low density } \\
5.0 \times 10^{3}\end{array}$ \\
& cells/inoculum & cells/inoculum \\
\hline 10\% RPMI & $3.5 \pm 0.08 \times 10^{6}$ & $\begin{array}{c}3.5 \pm 0.2 \times 10^{6} \\
\text { ATCC medium 745 }\end{array}$ \\
\hline
\end{tabular}

TABLE III. MGT (hr) of Tritrichomonas mobilensis in both high- and low-density cultures and in 2 types of media. Note the positive correlation between trichomonad density at inoculation and MGT.

\begin{tabular}{|c|c|c|}
\hline & \multicolumn{2}{|c|}{ Mean generation time (hr) } \\
\hline & $\begin{array}{l}\text { High density } \\
5.0 \times 10^{5} \\
\text { cells/inoculum }\end{array}$ & $\begin{array}{c}\text { Low density } \\
5.0 \times 10^{3} \\
\text { cells/inoculum }\end{array}$ \\
\hline $10 \%$ RPMI & $17.3 \pm 0.2$ & $5.1 \pm 0.05$ \\
\hline ATCC medium 745 & $15.4 \pm 0.2$ & $4.9 \pm 0.03$ \\
\hline
\end{tabular}

point, $10 \%$ RPMI medium is a more desirable medium because of its long shelf life and its delivery in sterile, prepared form. Moreover, the basic pH of RPMI 1640 medium (7.5) is precisely the $\mathrm{pH}$ at which trichomonads such as T. mobilensis and T. foetus are best cultured. Although FBS can be moderately expensive, it is used in limited quantities and stores well. Conversely, preparing ATCC medium 745 is a labor-intensive and costly exercise, considering that a batch will last only 14 days. Additionally, the presence of agar in ATCC medium 745 facilitates bacterial growth; so, if cultures become contaminated, they are nearly impossible to reaxenize. Finally, the increased viscosity of ATCC medium 745 makes its use impractical if cell motility is being investigated or considered. If, however, one's objective in culturing trichomonads is short-term and oriented toward building cell density, then ATCC medium 745 may prove to be a suitable choice because at $48 \mathrm{hr}$, maximum cell density was found to be significantly greater in ATCC medium 745 (4.5 million per milliliter in 745 vs. 3.5 million per milliliter in $10 \%$ RPMI, $P<0.0001)$.

\section{LITERATURE CITED}

Castro-Garza, J., F. Anaya-Velasquez, S. Said-Fernandez, and M. T. GonZALES-GarzA. 1996. Comparable growth of a Trichomonas vaginalis strain in PEHPS and TYI-S-33 media. Archives of Medical Research 27: 567-569.

Culberson, D. E., F. F. Pindak, W. A. Gardner, and B. M. Honigberg. 1986. Tritrichomonas mobilensis $\mathrm{n}$. sp. (Zoomastigophorea: Trichomonadida) from the Bolivian squirrel monkey Saimiri boliviensis boliviensis. Journal of Protozoology 33: 301-304.

Diamond, L. S., D. R. Harlow, and C. C. Cunnick. 1978. A new medium for the axenic cultivation of Entamoeba histolytica and other Entamoeba. Transactions of the Royal Society of Tropical Medicine and Hygiene 72: 431-432.

Gelbart, S. M., J. L. Thomason, P. J. Osypowski, A. V. Kellet, J. A. JAMES, AND F. F. BROEKHUIZEN. 1990. Growth of Trichomonas vaginalis in commercial culture media. Journal of Clinical Microbiology 28: 962 .

Johnson, G. T., AND M. H. TRussell. 1944. Physiology of bacteria-free T. vaginalis VII. Temperature in relation to survival and generation time. Proceedings of the Society of Experimental Biology and Medicine 57: 252-254.

Kostara, I., H. Carageorgiou, D. Varonos, and S. TZannetis. 1998. 
Growth and survival of Trichomonas vaginalis. Journal of Medical Microbiology 47: 555-560.

Krieger, J. N., M. R. Tam, C. E. Stevens, I. O. Nielson, J. Hale, N. B. KiVIat, AND K. K. Holmes. 1988. Diagnosis of trichomoniasis: Comparison of conventional wet-mount examination with cytologic studies, cultures and monoclonal antibody staining of direct specimens. Journal of the American Medical Association 259: 1223-1227.

Lossick, J. G. 1988. The diagnosis of vaginal trichomoniasis. Journal of the American Medical Association 259: 1230.

Meysick, K. C., AND G. E. Garber. 1990. Growth of Trichomonas vaginalis in a serum-free McCoy cell culture system. Journal of Parasitology 76: 926-928.

RaINIS, K. G. 1976. Studying an axenic culture of Tritrichomonas augusta. In Ward's Natural Science Establishment, Inc. bulletin, vol. 16, no. 102, winter. Ward's Natural Science Establishment, New York, New York.

Thomason, J. L., S. M. Gelbart, J. F. Sobun, M. B. Schulien, and P. R. HAMiLTon. 1988. Comparison of four methods to detect Trichomonas vaginalis. Journal of Clinical Microbiology 26: 18691870. 